Case Report

\title{
ENTERIC MYOCARDITIS: A CASE REPORT
}

\author{
Kawkab Mahmud, AKM Musa, AKM Shaheen Ahmed, Khwaja Nazimuddin, RSC Sarker \\ Department of Internal Medicine, Ibrahim Medical College \& Bangladesh Institute of \\ Research and Rehabilitation in Diabetes, Endocrine and Metabolic Disorders (BIRDEM)
}

\begin{abstract}
Enteric fever commonly causes fatality from abdominal complications or toxemia but it can also cause death from complications of myocarditis albeit rarely. In September, 2005 a 22 year old man was admitted in BIRDEM with the features of pneumonia. Later on, the patient developed acute left ventricular failure and ultimately diagnosed as a case of drug resistant enteric fever with myocarditis

Ibrahim Med. Coll. J. 2007; 1(1): 34-37
\end{abstract}

\section{Introduction}

Enteric fever still affects 17 million people per year worldwide ${ }^{1}$. They are endemic in the Indian subcontinent, southeast and far East Asia, the Middle East, Africa, Central America and South America where the sanitary conditions are poor ${ }^{2}$. In the United States the rate of enteric fever among patients with HIV is 60 times greater than those of the general population $^{3}$.

Based on DNA studies, all salmonellae are now considered a single species ( $S$ choleraesuis), separated into 7 distinct subgroups. Multiple serotypes of Salmonella cause the syndrome of enteric fever, of which typhoid fever is the best studied and described ${ }^{4,5}$. Caused by Salmonella typhi and occurring only in humans, typhoid fever is a severe multisystem illness and potentially fatal if untreated. Death may occur from overwhelming toxemia, myocarditis, intestinal hemorrhage, or perforation.

Toxic myocarditis is reported in 1-5\% of patients of typhoid fever ${ }^{2}$. A study done in the department of Medicine, KMC, Mangalore, India in a series of 100 bacteriologically or serologically proved enteric fever 7 cases were found with clinical evidence of myocarditis and 46 cases with ECG evidence of myocarditis ${ }^{6}$. Those with systemic complications had the highest chance of having myocarditis $(\mathrm{p}<0.01)$. So, it is well established that, ECG must be recorded in all cases of enteric fever. Also those with ECG changes must be observed carefully for clinical evidence of myocarditis.

\section{Case report}

In September 2005, a 22 year old febrile man was admitted in the department of internal medicine, BIRDEM with the complaints of productive cough and exertional dyspnoea. He was febrile for last 10 days; fever was high grade intermittent in nature, associated with mild headache and myalgia. Highest temperature recorded was $105^{\circ} \mathrm{F}$. For the last 5 days he developed cough, first mucoid then becoming productive along with progressive dyspnoea later on orthopnoea. He gave history of loose motions 2-3 times a day for the last 3 days but there was no vomiting. He was non-smoker, non asthmatic. He refused any recent travel abroad, or to the hill-tracts. He took a course of oral ciprofloxacin 500mg bid for 5 days.

On admission he was conscious, icteric and dyspnoeic. He felt better on propped up position. Respiratory rate was 33 breaths/min, pulse 100/ min and blood pressure 100/60 mm of $\mathrm{Hg}$. He was not cyanosed or anaemic and there was no digital clubbing or oedema.

Systemic examination revealed fine crepitations in mid and lower zone of both lung fields with vesicular breath sound. Right hypochondrium was mildly tender. Liver, spleen and lymph nodes were not palpable.

So our provisional diagnosis was atypical pneumonia. Viral hepatitis and leptospirosis was kept as differentials.

Address for Correspondence:

Dr. Kawkab Mahmud, Department of Internal Medicine, Ibrahim Medical College \& BIRDEM

122 Kazi Nazrul Islam Avenue, Shahbag, Dhaka-1000 
On routine investigations, complete blood count showed total count of WBC was at lower normal range with normal distribution and thrombocytopenia. (TC-4100, $\mathrm{P} / \mathrm{C}-33000, \mathrm{DC}-\mathrm{N}=79 \%, \mathrm{~L}=15 \%, \mathrm{M}=6 \%, \mathrm{E}=1 \%)$. Liver enzymes were slightly raised. SGPT-68 U/L, SGOT-72 U/L and serum bilirubin $3.2 \mathrm{mg} / \mathrm{dl}$. Blood urea and s. creatinine were normal. On the $10^{\text {th }}$ day blood, urine and sputum samples were sent for culture along with blood for triple antigen and viral markers. Bedside urine examination was normal. ECG showed nonspecific ST change. There was bilateral patchy opacities on CxR in mid and lower zone.

From the above parameters leptospirosis was excluded as WBC count was not raised. Bilateral patchy shadows and raised liver enzymes pointed towards atypical pneumonia or viral hepatitis. Enteric fever then came to focus. As the patient had already taken a course of ciprofloxacin, IV ceftriaxone was started empirically.

But on the $3^{\text {rd }}$ day of admission, i.e. $13^{\text {th }}$ day of the onset of fever, patient was still febrile, respiratory distress worsened. He also complained of palpitation. On examination there was undue tachycardia (142 b/ min) and tachypnoea (34 breath/min). On auscultation fine basal crepitations were found on both lungs. Urgent chest X-ray showed cardiomegaly with evidence of pulmonary edema along with the previous radiological findings. Arterial blood gas analysis revealed Type I respiratory failure. $\left(\mathrm{PO}_{2}=55 \mathrm{~mm}\right.$ of $\mathrm{Hg}, \mathrm{PCO}_{2}=23 \mathrm{~mm}$ of $\mathrm{Hg}, \mathrm{SaO}_{2}=76 \%, \mathrm{pH}=7.45$, $\left.\mathrm{HCO}_{3}=20 \mathrm{mmol} / \mathrm{L}\right)$. Viral markers for hepatitis were negative.

All these clinical features suggested acute pulmonary oedema. Patient's dyspnoea rapidly improved after administering IV frusemide. So the next plan was echocardiography and cardiac enzymes to prove our suspicions.

Then investigations supported the clinical suspicion. Echocardiography revealed global hypokinesia with ejection fraction only $37 \%$. CPK- 583u/l, CK-MB 70u/ 1, S. LDH-1510 u/1. Troponin-I was found normal. Diuretic was continued. On the $4^{\text {th }}$ day patient was not dyspnoeic any more but fever still persisting with cough.

Finally the c/s reports were available which showed growth of Salmonella typhi in blood. No growth was found in stool and urine.

So we reached our final diagnosis-Enteric fever with myocarditis with acute left ventricular failure.
Inj. Ceftriaxone was continued. Fever subsided after 16 days of onset. Patchy shadows disappeared in CxR and general condition of the patient improved.

\section{Discussion}

Myocarditis is used to describe simply as an inflammatory process with necrosis involving myocardium. According to Dallas criteria, the diagnosis of active myocarditis is defined as an inflammatory infiltrate of the myocardium with injury to the adjacent myocyte not typical for ischaemic damage associated with coronary artery disease. It usually forms part of a generalized infection, so far most commonly initiated by viral infection but can also be due to drugs, toxin, hypersensitivity reaction, collagen vascular disease and autoimmune reaction and less commonly with other infections like bacteria, rickettsia, spirochete, fungi, protozoa.

Clinically most often myocarditis is asymptomatic. Spectrum of clinical expression varies from mild local inflammation to fulminant congestive cardiac failure also including dizziness, syncope, palpitation caused by atrial and ventricular arrhythmia. In our case the patient presented with typical symptoms of left ventricular failure. He improved after empirical treatment with diuretics which prompted us towards further investigations which were clearly suggestive of myocarditis. Those included global hypokinesia in echocardiography, raised cardiac enzymes. His ECG was normal except sinus tachycardia.

ECG changes of myocarditis are often nonspecific usually appearing only in the first two weeks of illness. Commonest ECG abnormality was Q-Tc prolongation (29\%) followed by ST-T changes (20\%), bundle branch block (7\%), first degree A-V Block and arrhythmia $(2 \%)^{6}$. Other evidence for myocarditis include myocardial imaging, cardiac catheterization. Endomyocardial biopsy is considered the gold standard. But according to the 'Myocarditis Treatment Trial' it is no longer mandatory in the evaluation of unexplained heart failure.

This was a case of myocarditis due to enteric fever which was confirmed by blood culture sensitivity report. Usually diagnosis of enteric fever is suggested by assays that identify Salmonella antibodies, antigens, or DNA and is then confirmed by isolation of the organism. The most sensitive method of isolating $S$ typhi is obtaining a bone marrow aspirate (BMA) 
culture, positive in $90 \%$ cases $^{7}$. Blood, urine, and stool cultures are still frequently used but the yield is only about $70 \%{ }^{8}$. Rectal swab and bile from duodenal string test can also be used ${ }^{8,9}$. The Widal reaction is indicative in only $40-60 \%$ of patients during admission ${ }^{10}$. Although not commercially available, DNA probes have been developed for identifying $S$ typhi from bacterial culture isolates and directly from blood ${ }^{11}$.

Our patient improved with ceftriaxone, diuretics and bed rest. He did not respond to oral ciprofloxacin though this drug combines a lower documented resistance rate with excellent penetration into macrophages and the biliary system ${ }^{12}$. Since $1989, S$ typhi strains with simultaneous plasmid-mediated resistance to chloramphenicol, ampicillin, and cotrimoxazole have emerged and spread rapidly in the Indian subcontinent and parts of Southeast Asia ${ }^{13,19}$. Between $10 \%$ and $20 \%$ of patients treated with antibiotics have a relapse after initial recovery. Thus now the fluoroquinolones and the third-generation cephalosporins are the antibiotics of choice to treat these multidrug-resistant (MDR) strains, both in children and adults ${ }^{14-16}$. Furazolidone and Azithromycin are also used to treat typhoid in children in some parts of the developing world ${ }^{17,18}$.

Case fatality rates of $10-50 \%$ have been reported from endemic countries when diagnosis is delayed or in cases of severe typhoid fever not treated with highdose corticosteroid therapy and antibiotics ${ }^{20}$. The two most common complications of enteric fever are intestinal hemorrhage and perforation ${ }^{21}$. Among other complications, pancreatitis and simultaneous acute renal failure and hepatitis, cholangitis, meningism, encephalomyelitis, subclinical disseminated intravascular coagulation, osteomyelitis, arthritis have been reported ${ }^{22-26}$. Early antibiotic therapy has reduced the rate of these systemic complications transforming a previously life threatening illness into a short time febrile illness with negligible fatality.

Parenteral corticosteroid is recommended in severe typhoid fever with shock or depressed level of consciousness. As far our case is concerned, supportive treatment for myocarditis included absolute bed rest and diuretics. Judicious use of corticosteroids is indicated in selected cases of severe myocarditis. In conclusion, our case again emphasizes the utmost importance of early and proper use of antibiotic therapy in determining the prognosis of disease.

\section{References}

1. World Health Organization: Background document: the diagnosis, treatment, and prevention of typhoid fever. Geneva, Switzerland: 2003.

2. Theodore Curtis, David T Wheeler: Typhoid Fever. Update Sept 2005; eMedicine.

3. Ryan CA, Hargrett-Bean NT, Blake PA: Salmonella typhi infections in the States, 1975-1984: increasing role of foreign travel. Rev Infect Dis 1989: 11(1): 1-8.

4. Crosa JH, Brenner DJ, Ewing WH, Falkow S: Molecular relationships among Salmonelleae. J Bacteriol 1973 Jul; 115(1): 307-156.

5. Farmer JJ: Enterobacteriaceae: introduction and identification. In: Murray PR, Baron EF, Pfaller MA, eds. Manual of Clinical Microbiology. 6th ed. Washington, DC: American Society for Microbiology; 1995: 438-49.

6. Prabha A, Mohanan, Pereira P, Raghuveer CV; Myocarditis in enteric fever; Indian J Med Sci, 1995 Feb; 49(2): 28-31.

7. Hoffman SL, Edman DC, Punjabi NH, et al: Bone marrow aspirate culture superior to streptokinase clot culture and $8 \mathrm{ml} \mathrm{1:10} \mathrm{blood-to-broth} \mathrm{ratio} \mathrm{blood} \mathrm{culture}$ for diagnosis of typhoid fever. Am J Trop Med Hyg 1986 Jul; 35(4): 836-9.

8. Gilman RH, Terminel M, Levine MM, HernandezMendoza P, Hornick RB.; Relative efficacy of blood, urine, rectal swab, bone-marrow, and rose-spot cultures for recovery of Salmonella typhi in typhoid fever; Lancet. 1975 May 31; 1(7918): 1211-3.

9. Duodenal string-capsule culture compared with bonemarrow, blood, and rectal- swab cultures for diagnosing typhoid and paratyphoid a fever. J Infect Dis 1984 Feb; 149(2): 157-61.

10. Hoffman SL, Flanigan TP, Klaucke D, et al: The Widal slide agglutination test, a valuable rapid diagnostic test in typhoid fever patients at the Infectious Diseases Hospital of Jakarta. Am J Epidemiol 1986 May; 123(5): 869-75.

11. Rubin FA, McWhirter PD, Punjabi NH, et al: Use of a DNA probe to detect Salmonella typhi in the blood of patients with typhoid fever. J Clin Microbiol 1989 May; 27(5): 1112-4.

12. Stanley PJ, Flegg PJ, Mandal BK, Geddes AM: Open study of ciprofloxacin in enteric fever. J Antimicrob Chemother 1989 May; 23(5): 789-91.

13. Butler T, Rumans L, Arnold K: Response of typhoid fever caused by Chloramphenicol-susceptible and chloramphenicol-resistant strains of Salmonella typhi to treatment with trimethoprim-sulfamethoxazole. Rev Infect Dis 1982 Mar-Apr; 4(2): 551-61. 
14. Soe GB, Overturf GD: Treatment of typhoid fever and other systemic salmonelloses with cefotaxime, ceftriaxone, cefoperazone, and other newer cephalosporins. Rev Infect Dis 1987 Jul-Aug; 9(4): 719-36.

15. Tran TH, Bethell DB, Nguyen TT, et al: Short course of ofloxacin for treatment of multidrug-resistant typhoid. Clin Infect Dis 1995 Apr; 20(4): 917-23.

16. Gupta A: Multidrug-resistant typhoid fever in children: epidemiology and therapeutic approach. Pediatr Infect Dis J 1994 Feb; 13(2): 134-40.

17. Carcelen A, Chirinos J, Yi A: Furazolidone and chloramphenicol for treatment of typhoid fever. Scand J Gastroenterol Suppl 1989; 169: 19-23.

18. Frenck RW, Nakhla I, Sultan Y, et al: Azithromycin versus ceftriaxone for the treatment of uncomplicated typhoid fever in children. Clin Infect Dis 2000; 31: 134-1138.

19. Fever in Anand AC, Kataria VK, Singh W, Chatterjee SK: Epidemic multiresistant enteric eastern India. Lancet 1990 Feb 10; 335 (8685): 352.

20. Woodward TE, Hall HE, Dias-Rivera R, et al: Treatment of typhoid fever. II. Control of clinical manifestations with cortisone. Ann Intern Med 1951; 34: 10-9.
21. Rowland HA: The complications of typhoid fever. J Trop Med Hyg 1961; 64: 143-8.

22. Khosla SN: Typhoid hepatitis. Postgrad Med J 1990 Nov; 66 (781): 923-5.

23. Khan M, Coovadia Y, Sturm AW: Typhoid fever complicated by acute renal failure and hepatitis: case reports and review. Am J Gastroenterol 1998 Jun; 93(6): 1001-3

24. Hermans P, Gerard M, van Laethem Y, et al: Pancreatic disturbances and typhoid fever. Scand J Infect Dis 1991; 23(2): 201-5.

25. Baker NM, Mills AE, Rachman I, Thomas JE: Haemolytic-uraemic syndrome in Typhoid fever. $\mathrm{Br}$ Med J 1974 Apr 13; 2(910): 84-7.

26. Ramachandran S, Wickremesinghe HR, Perera MV: Acute disseminated encephalomyelitis in typhoid fever. Br Med J 1975 Mar 1; 1(5956): 494-5.

27. Hanel RA, Aravjo JC, Antoriuk A, et al: Multiple brain abscesses caused by solmonella typhi: Case report. Surg Nevrol 2003; 53(i): 86-90.

28. Julia J, Canet JJ, Lacasa XM, et al: Spantoneous spleen rupture during typhoid fever. Int J Intect Dis 2000; 4(2): 108-9. 